УДК 338.91

Т.А. Бородина, Г.Г. Бояджан

DOI: $10.36718 / 2500-1825-2019-4-10-24$

\title{
ТЕОРЕТИЧЕСКИЕ ОСНОВЫ СТРУКТУРИЗАЦИИ ЭКОНОМИЧЕСКОГО ПРОСТРАНСТВА
}

\section{T.A. Borodina, G.G. Boyadzhan \\ THEORETICAL BASES OF ECONOMIC SPACE STRUCTURING}

В статье рассмотрены теоретические подходы к трактовке таких категорий, как «экономическое пространство», «структура экономического пространства», «структурирование экономического пространства». Методологической основой исследования является диалектический метод, предусматривающий изучение данной категории в развитии, взаимосвязи и взаимозависимости. Вместе с тем использовались общенаучные и специфические методы исследования. Авторами на основании монографических исследований обобщены с точки зрения эволюции человеческого общества территориальный, ресурсный, процессный, информационный и институциональный подходы, исследованы заложенные в них основополагающце принципы. Полученные результаты позволяют сделать вывод, что в основе трактовок экономического пространства при любом подходе заложен экономический интерес участников, основанный на потребностях людей, как первичных, характеризующих физиологические и экзистенциальные потребности, так и вторичных, обуславливаемых социумом, территориальными и социально-культурными особенностями. Предложено выделять понятия макроструктуры и микроструктуры социально-экономического пространства, так как экономика региона должна обладать неким минимальным уровнем сложности и разнообразия. С экономической точки зрения усиление какой-то одной, наиболее эффективной отрасли хозяйства в тех или иных районах является положительным моментом. Тем не менее, это не должно происходить за счет упрощения экономической структуры, отказа от малых по вкладу в общую валовую добавленную стоимость производств. При этом структурированность пространства с социально-экономической точки зрения должна учитывать как факторы окружающей среды, так и административно-правовые, экономические и социально-культурные условия той или иной территории, что позволяет комплексно применять рассмотренные теоретические подходы.

Ключевые слова: экономическое пространство, структура, ресурсы, экономические процессы, информация, институты, структурирование, структура социально-экономического пространства. 


\section{Социально-экономический и әуманитарный журнал Красноярского ГАУ. 2019. № 4}

In the study theoretical approaches to the interpretation of such categories as "economic space", "economic space structure" "and structuring economic space" are considered. Methodological basis of the research is dialectic method providing studying of this category in the development, interrelation and interdependence. At the same time general scientific and specific methods of the research are used. The authors on the basis of monographic researches generalized from the point of view of evolution of human society territorial, resource, process, information and institutional approaches, the fundamental principles underlain in them. The results received allow drawing the conclusion that at the heart of interpretation of economic space at any approach economic interest of participants based on the needs of the people as primary, characterizing physiological and existential requirements, and secondary requirements caused by the society, territorial and welfare features is put forward. It is offered to allocate the concepts of macrostructure and microstructure of social and economic space as the economy of the region has to possess a certain minimum level of complexity and variety. From economic point of view strengthening of some, most effective branch of economy in these or those areas is a positive moment. However, this should not happen at the expense of simplifying the economic structure, giving up small contributions to the total gross value of added production. Thus the structure of space from social and economic point of view has to consider both environment factors, and administrative and legal, economic and welfare conditions of this or that territory that allows to apply considered theoretical approaches in a complex.

Keywords: economic space, structure, resources, economic processes, information, institutes, structuring, structure of social and economic space.

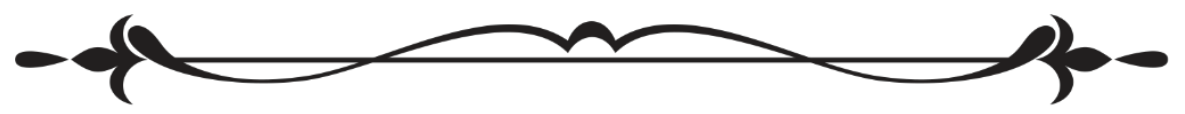

Введение. Развитие социально-экономической сферы деятельности человека создает ряд потребностей на соответствующих уровнях:

-государство - обеспечение продовольственной безопасности территории;

•бизнес - потребность в развитии производства и реализации продукции на рынки сбыта;

- население - обеспечение потребности в трудоустройстве за счет развития производственной сферы территории, а также реализация излишков продукции личных подсобных хозяйств.

Существенную помощь в удовлетворении данных потребностей и решений народнохозяйственных задач может оказать правильная структурированность пространства с социально-экономической точки зрения, учитывающая как факторы окружающей среды, так и административноправовые, экономические и социально-культурные условия той или 
иной территории. При этом понятие «структура» является распространенным и может употребляться в научном и философском обиходе, что делает его многофакторной категорией и требует конкретизации и изучения самостоятельной роли того или иного типа структуры с учетом прикладного характера трактовки. Кроме того, разные типы структур также требуют своих, свойственных им, специфических приемов и методов изучения.

Цели и задачи исследования. Целью исследования является обобщение теоретических подходов к трактовке категории «экономическое пространство», для чего были рассмотрены территориальный, ресурсный, процессный, информационный и институциональный подходы, исследованы заложенные в них принципы.

Результаты исследования и их обсуждение. Обобщая словарное толкование дефиниции «структура», можно отметить, что в общепринятом понимании она представляет собой взаиморасположение и связь частей, составляющих что-либо целое, т. е. устройство, организацию, строение чего-либо. Также в литературных источниках понятие структуры часто соотносится с понятиями системы и организации, однако единая точка зрения на соотношение этих понятий отсутствует. В экономических и юридических словарях структура представляется в виде разделения экономики, экономического объекта или экономической категории на составные части по определенным признакам, установлением взаимосвязей между этими частями. Таким образом, структуризация чего-либо может быть определена в зависимости от самого изучаемого объекта с рассмотрением всего множества его проявлений, таких как элементы, строение, связи, функции и пр.

Любая сельскохозяйственная производственная единица, независимо от организационно-правовой формы, вида деятельности и размеров производства, представляет собой открытую систему, которая получает из внешней среды ресурсы и поставляет обратно свой продукт. Структурированность пространства позволяет экономическим субъектам понять, что в нем находится, как взаимодействуют его элементы и как с ними можно успешно выстраивать взаимосвязи. При этом внешняя среда организации или хозяйственная среда представляет собой некое «вместилище» протекающих экономических процессов и явлений, которое в научной литературе рассматривается как «экономическое пространство», и его структуризация может быть определена в зависимости от того, что понимается под данной категорией и какие цели поставлены перед исследователем.

На основании монографических исследований можно сделать вывод, что на сегодняшний день нет единых взглядов на содержание как экономического пространства, так и его структуризации.

Основываясь на разработках Г.Х. Батова [1], Р.Ф. Гатауллина, А.Г. Каримова, А.Г. Комарова [2-4], в качестве доминирующих подходов 


\section{Социально-экономический и әуманитарный журнал Красноярского ГАУ. 2019. № 4}

разных исследователей можно выделить: территориальный, ресурсный и информационный, - при этом последние дополнительно вводят также процессный подход.

А.Ю. Волошина дополняет данные подходы факторной концепцией экономического пространства [5], в рамках которой свои исследования вели, в частности, П.А. Минакир и А.Н. Демьяненко [6 , с. 15- 16], В. Каспер. Однако, по мнению авторов, в основе данного подхода все также лежит ресурсный потенциал территории, который кроме природных ресурсов дополнен трудовыми ресурсами и ресурсами капитала. При этом сложившиеся подходы к определению понятия «экономическое пространство» определяются эволюцией человеческого общества, что находит свое отражение в трактовке терминов.

В основе территориального подхода лежит понимание пространства как территории, в рамках которой существуют экономические объекты, осуществляющие связи и использующие для реализации своих целей имеющийся на данной территории природно-ресурсный потенциал. При этом часто наблюдается подмена одного понятия другим и пространство приобретает некоторые географические рамки. Также имеет место понимание пространства как в широком смысле слова в виде совокупности территории государства, включая сушу и акватории, так и в узком смысле как освоенная для ведения хозяйственной деятельности территория страны, участвующая в процессе производства, распределения, обмена и потребления товаров, работ, услуг [7, с. 361], что в свою очередь позволяет развивать тем самым различные виды экономической деятельности и создавать условия для развития производительных сил [8] (табл. 1).

Таблица 1

\section{Территориальный подход к трактовке категории «экономическое пространство»}

\begin{tabular}{|c|c|}
\hline Автор & Трактовка категории «экономическое пространство» \\
\hline 1 & 2 \\
\hline А.Г. Гранберг & $\begin{array}{l}\text { «...насыщенная территория, вмещающая множество объектов и } \\
\text { связей между ними: населенные пункты, промышленные пред- } \\
\text { приятия, хозяйственно освоенные и рекреационные площади, } \\
\text { транспортные и инженерные сети и т. д.» }[9, \text { с. 25] }\end{array}$ \\
\hline $\begin{array}{l}\text { Е. Лейзерович, } \\
\text { Г. Костинский, } \\
\text { Л.Б. Вардомский }\end{array}$ & $\begin{array}{l}\text { «Территории, в границах которых взаиморасположение каких- } \\
\text { либо вновь возникающих объектов предопределено предшест- } \\
\text { вующим развитием или набором твердых правил» [10] }\end{array}$ \\
\hline $\begin{array}{l}\text { В.Б. Самсонов, } \\
\text { С.А. Шапавалов }\end{array}$ & $\begin{array}{l}\text { Территориально обусловленное и организованное во времени на } \\
\text { партнерской основе согласование коллективных интересов, цен- } \\
\text { ностей и мотивов деятельности хозяйствующих субъектов... в со- } \\
\text { циоэкосистемах «природа-человек-общество» [11] }\end{array}$ \\
\hline
\end{tabular}




\begin{tabular}{|c|c|}
\hline & Окончание табл. 1 \\
\hline 1 & 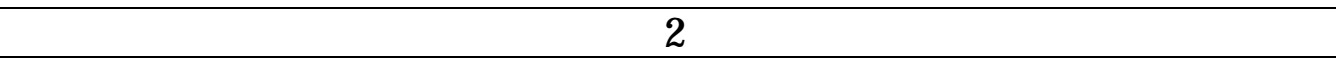 \\
\hline Э. Кочетов & $\begin{array}{l}\text { Пространство представляет территориальный контекст на уровне } \\
\text { экономики отдельных государств: геополитическое, геоэкономи- } \\
\text { ческое и геостратегическое [12] }\end{array}$ \\
\hline Е.А. Михуринская & $\begin{array}{l}\text { Территория, где проживает население, использующее для реали- } \\
\text { зации целей жизнедеятельности имеющийся на данной террито- } \\
\text { рии природно-ресурсный потенциал [8] }\end{array}$ \\
\hline $\begin{array}{l}\text { Н.Г. Багаутдинова, } \\
\text { И.Р. Гафуров }\end{array}$ & $\begin{array}{l}\text { «Территориально обособленная совокупность трансакций, в рам- } \\
\text { ках которых экономические агенты (домохозяйства, предприни- } \\
\text { мательские организации, государство, местное сообщество) реали- } \\
\text { зуют правомочия собственности на факторы и результаты произ- } \\
\text { водства, что обеспечивает реализацию их интересов» [13] }\end{array}$ \\
\hline $\begin{array}{l}\text { Е.Г. Анимица, } \\
\text { Н.М. Сурнина }\end{array}$ & $\begin{array}{l}\text { «Государственная территория, в пределах которой создается, ис- } \\
\text { пользуется и воспроизводится система жизнедеятельности чело- } \\
\text { века, осуществляется деятельность людей в целях удовлетворения } \\
\text { потребностей» [7]. При этом имеет место понимание пространства } \\
\text { как в широком смысле слова в виде совокупности территории го- } \\
\text { сударства, включая сушу и акватории, так и в узком смысле, как } \\
\text { освоенная для ведения хозяйственной деятельности территория } \\
\text { страны, участвующая в процессе производства, распределения, } \\
\text { обмена и потребления товаров, работ, услуг [14, с. 46] }\end{array}$ \\
\hline Л.Л. Зобова & $\begin{array}{l}\text { Организованная среда, возникающая «в результате взаимодейст- } \\
\text { вия (конкуренции) материальных субъектов на определенной тер- } \\
\text { ритории» }[15, \text { с. 8] }\end{array}$ \\
\hline Ю.Г. Лаврикова & $\begin{array}{l}\text { «динство физического базиса и социально-экономической среды } \\
\text { взаимодействия хозяйствующих субъектов, формируемой приме- } \\
\text { няемыми на территории механизмами регулирования экономики» } \\
{[16, \text { с.9] }}\end{array}$ \\
\hline
\end{tabular}

Развитие в XX веке транснациональных корпораций и процессов глобализации в мировом сообществе дало новый виток развития категории «экономического пространства», разрушая географические рамки, так как единые принципы реализации экономических интересов хозяйствующих субъектов стали устанавливаться не в пределах территориальных границ отдельного государства, а потребовали согласования государственной политики и заключения многосторонних договорных отношений группы государств.

Эволюция общества, по мнению О.А. Биякова, свидетельствует о снижении зависимости от фактора территориального расположения, поэтому территориальный подход к экономическому пространству был «актуален в доиндустриальную и индустриальную эпохи» [17, с. 102].

Территория для пространства стала выступать фундаментом, она представляет собой физическую основу экономического пространства, во многом определяющую его потенциал, но не является его исчерпывающей характеристикой, при этом пространство игнорирует официально установленные границы [15, с.11]. 


\section{Социально-экономический и әуманитарный журнал Красноярского ГАУ. 2019. № 4}

Однако следует отметить, что географическая среда при всех прочих условиях все же оказывает непосредственное влияние на развитие и социальных и экономических процессов, формирование издержек и финансовых результатов. На результаты сельскохозяйственного производства оказывают влияние: плодородие почв, количество осадков, температура воздуха, продолжительность вегетационного периода, т. е. все условия природной среды, которая служит естественным базисом хозяйственной деятельности людей [18, с. 11]. Еще К. Маркс отмечал [19, с. 30], что географическая среда влияет на человека опосредованно, через производственные отношения, возникающие на основе имеющихся производительных сил, одним из условий развития которых являются свойства этой среды.

Однако по мере развития рыночного хозяйства «географические условия, оставаясь важным фактором выбора места и вида экономической деятельности, уступили главенствующее место в качестве районообразующего начала экономическим условиям (сравнительным издержкам производства и распределения, предельной продуктивности труда и капитала, интенсивности и структуре спроса и пр.). Более того, пространственные экономические параметры стали активным элементом, деформирующим собственно географические условия» [20, с. 15- 16 ].

В основу ресурсного подхода к экономическому пространству исследователями положены экономические отношения, возникающие по распределению ресурсов (табл. 2).

Таблица 2

\section{Ресурсный подход к трактовке категории «экономическое пространство»}

\begin{tabular}{|l|l|}
\hline \multicolumn{1}{|c|}{ Автор } & \multicolumn{1}{|c|}{ Трактовка категории «экономическое пространство» } \\
\hline \multicolumn{1}{|c|}{} & \multicolumn{1}{|c|}{2} \\
\hline П. Кругман & $\begin{array}{l}\text { Абстрактный экономический ландшафт динамического распреде- } \\
\text { ления ресурсов в зависимости от конъюнктуры и их местоположе- } \\
\text { ния. В состав ресурсов/капитала включаются его организацион- } \\
\text { ный, институциональный и информационный виды [21] }\end{array}$ \\
\hline В.В. Радаев & $\begin{array}{l}\text { Совокупность «экономических действий», представляющих собой } \\
\text { определенную связь между целями и средствами, при этом одни- } \\
\text { ми из основных элементов экономического действия являются ог- } \\
\text { раниченность ресурсов и возможность их альтернативного упот- } \\
\text { ребления [22] }\end{array}$ \\
\hline В. Пефтиев & $\begin{array}{l}\text { Система отношений по использованию экономических ресурсов } \\
\text { [23] }\end{array}$ \\
\hline $\begin{array}{l}\text { И. Кучин } \\
\text { А. Лебедев }\end{array}$ & $\begin{array}{l}\text { Дискретное распределение источников сырья, предприятий по его } \\
\text { переработке и рынков реализации продукции [24] }\end{array}$ \\
\hline
\end{tabular}


Окончание табл. 2

\begin{tabular}{|c|c|}
\hline 1 & 2 \\
\hline $\begin{array}{l}\text { П.А. Минакир, } \\
\text { А.Н. Демьяненко }\end{array}$ & $\begin{array}{l}\text { Экономические регионы превратились в объективно формирую- } \\
\text { щиеся на экономическом фундаменте комплексы взаимосвязан- } \\
\text { ных и взаимодействующих экономических агентов... Их формиро- } \\
\text { вание определяется пространственной неоднородностью в распре- } \\
\text { делении не только природных ресурсов и труда, но и капитала } \\
\text { [6, с. 15- 16] }\end{array}$ \\
\hline В. Каспер & $\begin{array}{l}\text { Экономическое пространство учитывает наличие и активность } \\
\text { «мобильных» (работники, техника, материалы) и состояние «ста- } \\
\text { ционарных» (земля, дороги, расселение) факторов производства в } \\
\text { связи с имеющимися в каждой территории институтами, органи- } \\
\text { зациями и информацией [5] }\end{array}$ \\
\hline $\begin{array}{l}\text { В.В. Чекмарев, } \\
\text { А.В. Гульбасов }\end{array}$ & $\begin{array}{l}\text { Пространство, образованное: } \\
\text { а) физическими и юридическими лицами (субъектами), которые } \\
\text { для реализации своих экономических потребностей и выражаю- } \\
\text { щих эти потребности экономических интересов вступают в эконо- } \\
\text { мические отношения; } \\
\text { б) физическими и нефизическими объектами, являющимися ис-- } \\
\text { точниками экономических интересов и экономических отноше- } \\
\text { ний» [25, с. } 14]\end{array}$ \\
\hline
\end{tabular}

Недостатком ресурсного подхода можно назвать отражение лишь одной из составляющих экономического пространства, упуская из вида всю совокупность его характеристик.

Глобальное развитие информационных технологий во всем мире привело к новому пониманию экономического взаимодействия хозяйствующих субъектов. При информационном подходе к пониманию экономического пространства в качестве основного ресурса экономических субъектов выступает информация и возникающие между ними информационные потоки, что и формирует экономическое пространство. Экономическое пространство формируется через соперничество экономических агентов, обладающих конкурентными преимуществами в различного рода информации (табл. 3).

При этом О.А. Бияков считает информационный подход к экономическому пространству лишь частным случаем процессного подхода. Автор определяет экономическое пространство как отношения между экономическими процессами субъектов хозяйствования и совокупным экономическим процессом (V-процессом) по формированию возможных результатов экономической деятельности. При этом V-процесс может существовать, только если одновременно выполняются три условия: для экономических субъектов есть единая институциональная среда, между ними наличествуют тесные связи, а экономическое время частных процессов V-процесса синхронизировано [30] (табл. 4). 


\section{Социально-экономический и әуманитарный журнал Красноярского ГАУ. 2019. № 4}

\section{Информационный подход к трактовке категории «экономическое пространство»}

\begin{tabular}{|l|l|}
\hline \multicolumn{1}{|c|}{ Автор } & \multicolumn{1}{|c|}{ Трактовка категории «экономическое пространство» } \\
\hline С. А. Дятлов & $\begin{array}{l}\text { Информационное соперничество (информационно-идеологи- } \\
\text { ческое, научно-образовательное, сервисно-технологическое, орга- } \\
\text { низационно-управленческое) экономических агентов, обладаю- } \\
\text { щих конкурентными преимуществами в различного рода инфор- } \\
\text { мации [26, с. 8] }\end{array}$ \\
\hline Г. Шибусава & $\begin{array}{l}\text { Некоторая коммерческая часть Интернета, посредством которой } \\
\text { осуществляется управление потоками произведенных товаров [27] }\end{array}$ \\
\hline С. Паринов & $\begin{array}{l}\text { Әкономические агенты, под которыми понимаются все те же субъ- } \\
\text { екты хозяйствования, обмениваясь сигналами в процессе хозяйст- } \\
\text { венной деятельности, формируют этим экономическое простран- } \\
\text { ство [28] }\end{array}$ \\
\hline Р. Шулер & $\begin{array}{l}\text { Исследовал влияние систем телекоммуникаций на структуру эко- } \\
\text { номического пространства крупного города [29] }\end{array}$ \\
\hline С. Парк & $\begin{array}{l}\text { Выделял ключевое значение сетевой организации экономики, } \\
\text { считая ее необходимым условием для формирования такой инно- } \\
\text { вационной среды, которая обеспечивает выравнивание регио- } \\
\text { нальных различий и экономический рост в каждом [29] }\end{array}$ \\
\hline
\end{tabular}

Таблица 4

\section{Процессный подход к трактовке категории «экономическое пространство»}

\begin{tabular}{|l|l|}
\hline \multicolumn{1}{|c|}{ Автор } & \multicolumn{1}{|c|}{ Трактовка категории «экономическое пространство» } \\
\hline O.А. Бияков & $\begin{array}{l}\text { Система отношений между субъектами, реализующими частные } \\
\text { экономические процессы, и субъектом совокупного экономическо- } \\
\text { го процесса (V-процессом) по формированию ожидаемых резуль- } \\
\text { татов их деятельности [17] }\end{array}$ \\
\hline О.П. Звягинцева & $\begin{array}{l}\text { Система, уровни которой «в разной степени заполнены реальны- } \\
\text { ми хозяйственными системами, формами их взаимодействия и } \\
\text { происходящими внутри них хозяйственными процессами, выра- } \\
\text { жающими их экономические отношения» [31] }\end{array}$ \\
\hline
\end{tabular}

Дополнительно к названным подходам Е.Г. Анимица и В.А. Сухих, О.В. Иншакова и Д.П. Фролова включают такие подходы, как хозяйственный (деятельностный) и институциональный, которые отмечают, что хозяйственное пространство может быть «измерено» с применением понятий институциональных теорий [14, с. 46, 32, с. 5] (табл. 5).

Данный подход также актуален для исследования вопросов структуризации сектора сельскохозяйственного микробизнеса, так как «институты оказывают активное влияние на пространственное развитие на всех его уровнях - от локального до глобального; институты всегда простран- 
ственно укоренены и имеют территориальную специфику; действуют в комбинации как с географическими, так и с другими ... факторами; наконец, институты не только адаптируются к средовым изменениям, но и инициируют их, конструируя ниши в экономическом пространстве» [33, c. 17-18].

H.M. Сурнина в качестве макроподходов к социально-экономическому пространству представляет социологический, глобалистический, геосистемный, геоурбанистический, цивилизационный (эволюционный, эволюционно-стадийный, цикличный), геоэкологический, геоэкономический, геоинформационный, геокультурный, когнитивный, геополитический подходы [34, с. 36].

Таблица 5

Институциональный подход к трактовке категории «экономическое пространство»

\begin{tabular}{|l|l|}
\hline \multicolumn{1}{|c|}{ Автор } & \multicolumn{1}{|c|}{ Трактовка категории «экономическое пространство» } \\
\hline А.А. Урунов & $\begin{array}{l}\text { Сфера деятельности экономических агентов и их отношений в } \\
\text { рамках фунционирующей институциональной среды, связанных } \\
\text { с удовлетворением их растущей потребностей [35] }\end{array}$ \\
\hline Д.П. Фролов & $\begin{array}{l}\text { «Иституты оказывают активное влияние на пространственное } \\
\text { развитие на всех его уровнях - от локального до глобального; ин- } \\
\text { ституты всегда пространственно укоренены и имеют территори- } \\
\text { альную специфику; действуют в комбинации как с географиче- } \\
\text { скими, так и с другими ...факторами; наконец, институты не толь- } \\
\text { ко адаптируются к средовым изменениям, но и инициируют их, } \\
\text { конструируя ниши в экономическом пространстве» [33] }\end{array}$ \\
\hline
\end{tabular}

Выводы. В целом необходимо отметить, что рассмотренные теоретические подходы к экономическому пространству позволяют исследовать данный предмет через отражение его характеристик и сущностных отличий от других видов пространства и способствуют более глубокому его пониманию, дополняя друг друга. Наблюдается смещение научного интереса от природного и географического районирования и размещения производственных сил к росту роли информационных факторов, связанных с глобальными изменениями в мире. В основе трактовок экономического пространства при любом подходе заложен экономический интерес участников, основанный на потребностях людей, как первичных, характеризующих физиологические и экзистенциальные потребности, так и вторичных, обуславливаемых социумом.

В силу данного фактора, по мнению авторов, при проведении дальнейшего исследования корректнее использовать понятие «социальноэкономическое пространство», под которым с учетом региональной составляющей будем понимать совокупность отношений, возникающих в связи с реализацией субъективных потребностей участников в рамках 


\section{Социально-экономический и әуманитарный журнал Красноярского ГАУ. 2019. № 4}

сложившегося социума, обусловленных его территориальными и социально-культурными особенностями. При этом под структурой социальноэкономического пространства региона можно понимать собирательное название характеристик макро- и микростроения, что позволяет выделять понятие:

•макроструктуры - позволяющую установить присутствие и распределение по объему экономического пространства ее основных элементов, присущих любой выделенной территории, их форму и расположение;

-микроструктуры - характеризуемую размерами, формой и взаимным расположением субъектов микробизнеса разных форм, видов деятельности, а также их количеством, размерами и прочими характеристиками.

Экономика региона должна обладать неким минимальным уровнем сложности и разнообразия. С экономической точки зрения усиление какой-то одной, наиболее эффективной отрасли хозяйства в тех или иных районах является положительным моментом. Тем не менее, это не должно происходить за счет упрощения экономической структуры, отказа от малых по вкладу в общую валовую добавленную стоимость производств.

\section{Литература}

1. Батов Г.X. Экономическое пространство: проблемы становления в регионе // Региональная экономика: теория и практика. - 2014. № 42. - C. 2- 11.

2. Каримов А.Г., Чувашаева Э.Р. К уточнению сущности и содержания категории «экономическое пространство»// Международный журнал прикладных и фундаментальных исследований. - 2014. № 10-2. - C. 62-67. - URL: http:// www.applied-research.ru/ ru/ article/ view?id=5998 (дата обращения: 18.02.2019).

3. Структуризация экономического пространства региона: сущность, факторы, проектирование: монография / под общ. ред. Р.Ф. Гатауллина; ИСЭИ УНЦ РАН. - Уфа, 2016. - 216 с.

4. Гатауллин Р.Ф., Каримов А.Г., Комаров А.Г. Экономическое пространство: содержание, единство и разрывы // Проблемы современной экономики. - 2014. - № 4. - С. 196- 200.

5. Волошина А.Ю. Пространство мегаэкономики: концептуальные основы идентификации в глобальной экономике // Вестн. ВолГУ. Сер. 3. Экономика. Экология. - 2013. - № 2. - URL: https://cyberleninka.ru/article/ n/ prostranstvo-megaekonomiki-kontseptualnye-osnovyidentifikatsii-v-globalnoy-ekonomike (дата обращения: 19.02.2019). 
6. Минакир П.А., Демъяненко А.Н. Пространственная экономика: эволюция подходов и методология // Экономическая наука современной России. - 2010. - № 3 (50). - С. 7- 26.

7. Анимица Е.Г., Сурнина Н.М. Экономическое пространство России: проблемы и перспективы // Экономика региона. - 2006. - № 3. C. 34- 46.

8. Михуринская E.A. Регион как форма организации экономического пространства. - URL: http:// www.rusnauka.com/ONG_2006/ Economics/ 17637.doc.htm.

9. Гранберг А.Г. Основы региональной экономики: учеб. для вузов. М.: Изд-во ГУ ВШЭ, 2000.

10. Ляпина М.В., Моисеева И.С. Экономическое пространство: сущность, функции, свойства. - URL: http://do.gendocs.ru/docs/index305839.html (дата обращения: 17.02.2019).

11. Чернецова Н.С. Природа и структура экономического пространства и экономические интересы / Изв. ПГПУ. Сер. Общественные науки. 2006. - № 2. - C. 64-68.

12. Кочетов Э.Г. Геоэкономика. Освоение мирового экономического пространства: учеб. для вузов. - М.: Норма, 2010. - 528 с.

13. Багаутдинова Н.Г., Гафуров И.Р. Изменение конфигурации экономического пространства региона на основе реализации потенциала промышленных районов // Российское предпринимательство. 2012. - № 2 (200). - C. 166- 171.

14. Анимица Е.Г., Сухих B.A. Пространственно-временная парадигма в социоэкономике: региональный аспект. - Пермь, 2007.

15. Зобова Л.Л. Территория и пространство: близнецы или двойняшки? // Региональная экономика: теория и практика. - 2008. № 33 (90). - C. 6- 12.

16. Лаврикова Ю.Г. Кластеры как рыночный институт пространственного развития экономики региона: автореф. дис. ... д-ра экон. наук. Екатеринбург, 2009.

17. Бияков О.А. Экономическое пространство: сущность, функции, свойства // Вестн. КузГТУ. - 2004. - № 2. - С. 101- 108.

18. Бородина T.A. Природно-климатические аспекты управления производственными издержками в молочном скотоводстве (на материалах Красноярского края) / Краснояр. гос. аграр. ун-т. - Красноярск, 2015. - $187 \mathrm{c}$.

19. Маркс К. Капитал // Маркс К., Энгельс Ф. Сочинения. - Т. 23. - М.: Политиздат, 1961.

20.Минакир П.А., Демъяненко А.Н. Пространственная экономика: эволюция подходов и методология // Экономическая наука современной России. - 2010. - № 3 (50). - С. 7- 26.

21. Кругман П., Обстфельд М. Международная экономика. Теория и политика. - М.: ЮНИТИ, 1997. 


\section{Социально-экономический и әуманитарный журнал Красноярского ГАУ. 2019. № 4}

22. Радаев В.В. Что такое «экономическое действие» // Экономическая социология. - 2002. - Т. 3, № 5. - С. 18- 25.

23. Игнатов В.Г., Бутов В.И. Регионоведение: методология, политика, экономика, право. - Ростов н/Д.: МарТ, 1998.

24. Ерохина E.A. Теория экономического развития: системносамоорганизационный подход. - Томск: Изд-во ТГУ, 1999.

25. Гульбасов А.В. Концепция экономического пространства и ее потенциал в исследовании экономических процессов и явлений: автореф. дис. ...канд. экон. наук. - Иваново, 2007.

26. Дятлов C.A. Сетевые эффекты и возрастающая отдача в информационно-инновационной экономике // Изв. Санкт-Петербург. гос. экон. ун-та. - 2014. - № 2(86). - С. 7- 11.

27. Кислюк М.Б., Сурнин В.С. Кузбасская модель реформирования экономики. - Кемерово: Кузбассвузиздат, 1995.

28. Паринов С.И. К теории сетевой экономики / ИЭОПП СО РАН. Новосибирск, 2002.

29. Каримов А.Г., Чувашаева Э.Р. К уточнению сущности и содержания категории «экономическое пространство» // Международный журнал прикладных и фундаментальных исследований. - 2014. № 10-2. - C. 62- 67. - URL: http:// www.applied-research.ru/ ru/article/ view?id=5998 (дата обращения: 18.02.2019).

30. Бияков O.A. Теория экономического пространства: методологический и региональный аспекты. - Томск: Изд-во ТГУ, 2004.

31. Чернецова Н.С. Природа и структура экономического пространства и экономические интересы // Изв. ПГПУ. Сер. Общественные науки. - 2006. - № 2. - С. 64- 68.

32. Иншаков О.В., Фролов Д.П. Институциональность пространства в концепции пространственной экономики // Пространственная экономика. - 2007. - № 1. - С. 5- 21.

33. Фролов Д.П. Имеют ли институты значение для пространственной экономики // Пространственная экономика. - 2015. - № 1. С. $14-37$.

34. Сурнина H.M. Пространственная экономика: проблемы теории, методологии и практики. - Екатеринбург: Изд-во УрГЭУ, 2003.

35. Урунов A.A. Оценки качества российского экономического пространства в условиях глобализации экономики: автореф. дис. ... канд. экон. наук. - URL: http:// economy-lib.com/ otsenki-kachestvarossiyskogoekonomicheskogo-prostranstva-v-usloviyah-globalizatsiiekonomiki\#ixzz31Oq. 


\section{Literatura}

1. Batov G.H. Jekonomicheskoe prostranstvo: problemy stanovlenija v regione // Regional'naja jekonomika: teorija i praktika. - 2014. - № 42. S. 2- 11.

2. Karimov A.G., Chuvashaeva Je.R. K utochneniju sushhnosti i soderzhanija kategorii «jekonomicheskoe prostranstvo» // Mezhdunarodnyj zhurnal prikladnyh i fundamental'nyh issledovanij. 2014. - № 10-2. - S. 62-67. - URL: http://www.appliedresearch.ru/ru/article/view?id=5998 (data obrashhenija: 18.02.2019).

3. Strukturizacija jekonomicheskogo prostranstva regiona: sushhnost', faktory, proektirovanie: monografija / pod obshh. red. R.F. Gataullina; ISJ eI UNC RAN. - Ufa, 2016. - 216 s.

4. Gataullin R.F., Karimov A.G., Komarov A.G. J ekonomicheskoe prostranstvo: soderzhanie, edinstvo i razryvy // Problemy sovremennoj jekonomiki. - 2014. - № 4. - S. 196- 200.

5. Voloshina A.Ju. Prostranstvo megajekonomiki: konceptual'nye osnovy identifikacii v global'noj jekonomike // Vestn. VolGU. Ser. 3. J ekonomika. J ekologija. - 2013. - № 2. - URL: https:// cyberleninka.ru/arti$\mathrm{cle/n}$ / prostranstvo-megaekonomiki-kontseptualnye-osnovy-identifikatsiiv-globalnoy-ekonomike (data obrashhenija: 19.02.2019).

6. Minakir P.A., Dem'janenko A.N. Prostranstvennaja jekonomika: jevoljucija podhodov i metodologija // J ekonomicheskaja nauka sovremennoj Rossii. - 2010. - № 3 (50). - S. 7- 26.

7. Animica E.G., Surnina N.M. J ekonomicheskoe prostranstvo Rossii: problemy i perspektivy // Jekonomika regiona. - 2006. - № 3. S. 34- 46.

8. Mihurinskaja E.A. Region kak forma organizacii jekonomicheskogo prostranstva. - URL: http://www.rusnauka.com/ONG_2006/Economics/ 17637.doc.htm.

9. Granberg A.G. Osnovy regional'noj jekonomiki: ucheb. dlja vuzov. M.: Izd-vo GU VShJ e, 2000.

10. Ljapina M.V., Moiseeva I.S. J ekonomicheskoe prostranstvo: sushhnost', funkcii, svojstva. - URL: http://do.gendocs.ru/docs/index-305839.html (data obrashhenija: 17.02.2019).

11. Chernecova N.S. Priroda i struktura jekonomicheskogo prostranstva i jekonomicheskie interesy / Izv. PGPU. Ser. Obshhestvennye nauki. 2006. - № 2. - S. 64- 68.

12. Kochetov J e.G. Geojekonomika. Osvoenie mirovogo jekonomicheskogo prostranstva: ucheb. dlja vuzov. - M.: Norma, 2010. - 528 s.

13. Bagautdinova N.G., Gafurov I.R. Izmenenie konfiguracii jekonomicheskogo prostranstva regiona na osnove realizacii potenciala promyshlennyh rajonov // Rossijskoe predprinimatel'stvo. - 2012. № 2 (200). - S. 166- 171. 


\section{Социально-экономический и әуманитарный журнал Красноярского ГАУ. 2019. № 4}

14. Animica E.G., Suhih V.A. Prostranstvenno-vremennaja paradigma v sociojekonomike: regional'nyj aspekt. - Perm', 2007.

15. Zobova L.L. Territorija i prostranstvo: bliznecy ili dvojnjashki? // Regional'naja jekonomika: teorija i praktika. - 2008. - № 33 (90). S. 6- 12.

16. Lavrikova Ju.G. Klastery kak rynochnyj institut prostranstvennogo razvitija jekonomiki regiona: avtoref. dis. ... d-ra jekon. nauk. Ekaterinburg, 2009.

17. Bijakov O.A. Jekonomicheskoe prostranstvo: sushhnost', funkcii, svojstva // Vestn. KuzGTU. - 2004. - № 2. - S. 101- 108.

18. Borodina T.A. Prirodno-klimaticheskie aspekty upravlenija proizvodstvennymi izderzhkami $\mathrm{v}$ molochnom skotovodstve (na materialah Krasnojarskogo kraja) / Krasnojar. gos. agrar. un-t. Krasnojarsk, 2015. - 187s.

19. Marks K. Kapital // Marks K., Jengel's F. Sochinenija. - T. 23. M.: Politizdat, 1961.

20. Minakir P.A., Dem'janenko A.N. Prostranstvennaja jekonomika: jevoljucija podhodov i metodologija // Jekonomicheskaja nauka sovremennoj Rossii. - 2010. - № 3 (50). - S. 7- 26.

21. Krugman P., Obstfel'd M. Mezhdunarodnaja jekonomika. Teorija i politika. - M.: J uNITI, 1997.

22. Radaev V.V. Chto takoe «jekonomicheskoe dejstvie» // J ekonomicheskaja so-ciologija. - 2002. - T. 3, № 5. - S. 18- 25.

23. Ignatov V.G., Butov V.I. Regionovedenie: metodologija, politika, jekonomika, pravo. - Rostov n/ D.: MarT, 1998.

24. Erohina E.A. Teorija jekonomicheskogo razvitija: sistemnosamoorganizacionnyj podhod. - Tomsk: Izd-vo TGU, 1999.

25. Gul'basov A.V. Koncepcija jekonomicheskogo prostranstva i ee potencial v issledovanii jekonomicheskih processov i javlenij: avtoref. dis. ... kand. jekon. nauk. - Ivanovo, 2007.

26. Djatlov S.A. Setevye jeffekty i vozrastajushhaja otdacha v informacionnoinnovacionnoj jekonomike // Izv. Sankt-Peterburg. gos. jekon. un-ta. 2014. - № 2(86). - S. 7- 11.

27. Kisljuk M.B., Surnin V.S. Kuzbasskaja model' reformirovanija jekonomiki. - Kemerovo: Kuzbassvuzizdat, 1995.

28. Parinov S.I. K teorii setevoj jekonomiki / IJ eOPP SO RAN. - Novosibirsk, 2002.

29. Karimov A.G., Chuvashaeva Je.R. K utochneniju sushhnosti i soderzhanija kategorii «jekonomicheskoe prostranstvo» // Mezhdunarodnyj zhurnal prikladnyh i fundamental'nyh issledovanij. 2014. - № 10-2. - S. 62-67. - URL: http:// www.appliedresearch.ru/ru/article/ view?id=5998 (data obrashhenija: 18.02.2019).

30. Bijakov O.A. Teorija jekonomicheskogo prostranstva: metodologicheskij i regional'nyj aspekty. - Tomsk: Izd-vo TGU, 2004. 
31. Chernecova N.S. Priroda i struktura jekonomicheskogo prostranstva i jekonomicheskie interesy // Izv. PGPU. Ser. Obshhestvennye nauki. 2006. - № 2. - S. 64- 68.

32. Inshakov O.V., Frolov D.P. Institucional'nost' prostranstva v koncepcii prostranstvennoj jekonomiki // Prostranstvennaja jekonomika. 2007. - № 1. - S. 5- 21.

33. Frolov D.P. Imejut li instituty znachenie dlja prostranstvennoj jekonomiki // Prostranstvennaja jekonomika. - 2015. - № 1. - S. 14- 37.

34. Surnina N.M. Prostranstvennaja jekonomika: problemy teorii, metodologii i praktiki. - Ekaterinburg: Izd-vo UrGJ eU, 2003.

35. Urunov A.A. Ocenki kachestva rossijskogo jekonomicheskogo prostranstva v uslovijah globalizacii jekonomiki: avtoref. dis. ... kand. jekon. nauk. - URL: http:// economy-lib.com/ otsenki-kachestvarossiyskogoekonomicheskogo-prostranstva-v-usloviyah-globalizatsiiekonomiki\#ixzz31Oq.

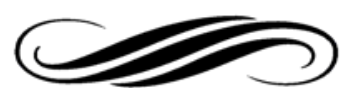

